\title{
Non-progressive cerebellar ataxia with previous acute cerebellar injury of undetermined origin: a puzzling neurological disorder
}

\author{
Ataxias cerebelares não-progressivas com lesão cerebelar aguda prévia de origem \\ indeterminada: um distúrbio neurológico enigmático
}

Hélio Afonso Ghizoni Teive

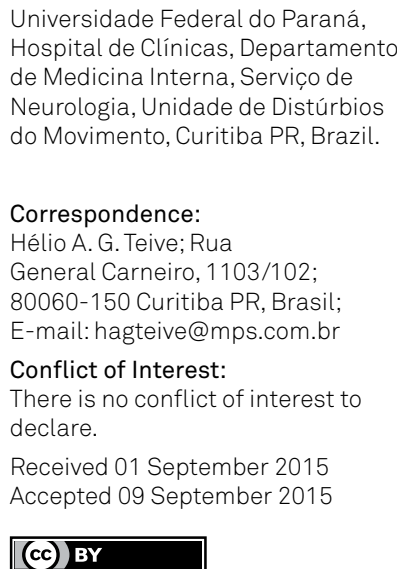

Universidade Federal do Paraná, Hospital de Clínicas, Departamento de Medicina Interna, Serviço de Neurologia, Unidade de Distúrbios do Movimento, Curitiba PR, Brazil.

Correspondence:

Hélio A. G. Teive; Rua

General Carneiro, 1103/102; 80060-150 Curitiba PR, Brasil; E-mail:hagteive@mps.com.br Conflict of Interest:

There is no conflict of interest to declare.

Received 01 September 2015 Accepted 09 September 2015

(cc) BY

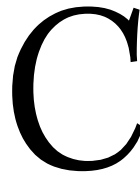

erebellar ataxias are a heterogeneous group of diseases and can be classified as primary and secondary, as well as hereditary and sporadic ${ }^{1}$.Primary cerebellar ataxias are subdivided into sporadic and hereditary ataxias ${ }^{1}$. The latter include congenital ataxias (such as Joubert's syndrome); autosomal recessive cerebellar ataxias (ARCAs), including Friedreich's ataxia and ataxia telangiectasia; autosomal dominant cerebellar ataxias, also known as spinocerebellar ataxias (SCAs), such as SCAs type 1, 2, 3, 6, 7 and 10); episodic ataxias; X-linked cerebellar ataxias; and mitochondrial ataxias. ${ }^{1}$ Idiopathic sporadic degenerative cerebellar ataxias include the cerebellar form of multiple system atrophy (MSA-C) and idiopathic late-onset cerebellar ataxias (ILOCA) ${ }^{1}$. Secondary, or acquired, ataxias result from a variety of exogenous or endogenous non-genetic causes, including those of a toxic (drug-induced cerebellar ataxia), paraneoplastic, immune-mediated, nutritional or infectious nature, as well as focal injury to the cerebellum ${ }^{1}$. Non-progressive cerebellar ataxias are a very rare, chronic neurological condition with different etiologies, including congenital cerebellar malformations (such as Joubert's syndrome) and inherited neurometabolic disorders (such as GLUT1 deficiency). They include sporadic cerebellar ataxias associated with infections (chickenpox virus, Epstein-Barr virus) and toxic agents (previous drug exposure) and autoimmune cerebellar ataxias ${ }^{2,3,4}$. A peculiar group of non-progressive cerebellar ataxias can be associated with previous acute or subacute cerebellar insult of unknown etiology ${ }^{5}$. In this issue of Arquivos de Neuro-Psiquiatria, Pinto et al. report an interesting and puzzling non-progressive cerebellar ataxia with previous acute cerebellar injury of undetermined origin ${ }^{5}$. The authors studied five adult patients with acquired non-progressive cerebellar ataxia (mean age of onset $=20.8$ years) associated with cerebellar or olivopontocerebellar atrophy who presented with previous acute or subacute onset (mean value $=10$ days) without a known etiology for the condition ${ }^{5}$. They discuss in great detail various possible etiologies of this mysterious condition, including neurogenic etiologies (either unidentified because of incomplete genetic investigation or associated with genetic diseases with mild phenotypes or formes frustes) and inborn errors of metabolism (undiagnosed because of incomplete screening), but failed to find a specific etiology in their series of patients 5 . While most published cases of non-progressive ataxia are described in early childhood, have a congenital etiology (e.g., cerebellar hypoplasia) and are frequently accompanied by mental retardation, a significant number of cases are unclassifiable ${ }^{2,3,4}$. In contrast, sporadic cerebellar ataxia with adult onset is associated with genetic, non-genetic and sporadic degenerative diseases ${ }^{6,7}$. In 2010, Klockgether published a very interesting study of sporadic ataxia with adult onset and discussed different etiologies of this condition, including genetic causes, with single gene mutations (e.g., Friedreich's ataxia and SCA type 6), and non-genetic causes (e.g., drug-induced cerebellar ataxia and immune-mediated cerebellar ataxia with cerebellar inflammation), as well as cases of multiple system atrophy type $\mathrm{C}$ and sporadic adultonset ataxia of unknown etiology (SAOA $)^{6}$. However, the cases of non-progressive cerebellar ataxia described by Pinto et al. are associated with previous acute or subacute onset of undetermined origin, and most started in the second decade of life ${ }^{5}$. One attractive hypothesis could be a non-progressive cerebellar ataxia due to previous acute viral cerebellitis or postinfectious 
cerebellar ataxia with an autoimmune mechanism. Specific serologic and genetic markers that allow a definite diagnosis are not yet available in most Brazilian public health institutions, and it is to be hoped that in the near future new, more cost-effective diagnostic methods can elucidate this rare, mysterious and enigmatic neurological condition. Indeed, mysterious neurological conditions of this kind are part of everyday neurological clinical practice around the world. In 2013, Kempster and Lees published a very interesting paper about neurology and detective writing, emphasizing the relationship between neurological investigation and detective mystery fiction, particularly the figure of the neurologist's alter ego, Sherlock Holmes ${ }^{8}$, who, like neurologists, is obsessive in his pursuit of the correct diagnosis ${ }^{8}$. However, in the condition known as non-progressive cerebellar ataxia with previous acute cerebellar injury of undetermined origin, the quotation incorrectly attributed to Sherlock Holmes could be changed to "Not so elementary, my dear Watson!"

\section{References}

1. Teive HAG, Ashizawa T. Primary and secondary ataxias. Curr Opin Neurol. 2015;28(4):413-22. doi:10.1097/WC0.0000000000000227

2. Esscher E, Flodmark O, Hagberg G, Hagberg B. Non-progressive ataxia: origins, brain pathology and impairments in 78 Swedish children. Dev Med Child Neurol. 1996;38(4):285-96. doi:10.1111/j.1469-8749.1996.tb12095.x

3. Steinlin M. Non-progressive congenital ataxias. Brain Dev. 1998;20(4):199-208.

4. Steinlin M, Zangger B, Boltshauser E. Non-progressive congenital ataxia with or without cerebellar hypoplasia: a review of 34 subjects. Dev Med Child Neurol. 1998;40(3):148-54.
5. Pinto WBV, Pedroso JL, Souza PVS, Albuquerque MVC, Barsottini OG. Non-progressive cerebellar ataxia and previous undetermined acute cerebellar injury: a mysterious clinical condition. Arq Neuropsiquiatr. 2015:73(10):823-27 doi:10.1590/0004-282X20150119

6. Klockgether T. Sporadic ataxia with adult onset: classification and diagnostic criteria. Lancet Neurol. 2010;9(1):94-104. doi:10.1016/S1474-4422(09)70305-9

7. Teive HAG, Munhoz RP, Ashizawa T. Inherited and sporadic ataxias. In: Albanese A, Jankovic J. Hyperkinetic movement disorders: differential diagnosis and treatment. Oxford:Wiley-Blackwell;2012. p. 279-95.

8. Kempster PA, Lees AJ. Neurology and detective writing. Pract Neurol. 2013;13:372-6. doi:10.1136/practneurol-2013-000597 